\title{
Statistical evaluation of transcriptomic data generated using the Affymetrix one-cycle, two-cycle and IVT-Express RNA labelling protocols with the Arabidopsis ATH1 microarray
}

\author{
Tara J Holman ${ }^{1 *+}$, Michael H Wilson ${ }^{1 \dagger}$, Kim Kenobi $^{1 \dagger}$, lan L Dryden ${ }^{1,2}$, T Charlie Hodgman $^{1}$, Andrew TA Wood ${ }^{1,2}$,
} Michael J Holdsworth ${ }^{1,3}$

\begin{abstract}
Background: Microarrays are a powerful tool used for the determination of global RNA expression. There is an increasing requirement to focus on profiling gene expression in tissues where it is difficult to obtain large quantities of material, for example individual tissues within organs such as the root, or individual isolated cells. From such samples, it is difficult to produce the amount of RNA required for labelling and hybridisation in microarray experiments, thus a process of amplification is usually adopted. Despite the increasing use of two-cycle amplification for transcriptomic analyses on the Affymetrix ATH1 array, there has been no report investigating any potential bias in gene representation that may occur as a result.
\end{abstract}

Results: Here we compare transcriptomic data generated using Affymetrix one-cycle (standard labelling protocol), two-cycle (small-sample protocol) and IVT-Express protocols with the Affymetrix ATH1 array using Arabidopsis root samples. Results obtained with each protocol are broadly similar. However, we show that there are 35 probe sets (of a total of 22810) that are misrepresented in the two-cycle data sets. Of these, 33 probe sets were classed as mis-amplified when comparisons of two independent publicly available data sets were undertaken.

Conclusions: Given the unreliable nature of the highlighted probes, we caution against using data associated with the corresponding genes in analyses involving transcriptomic data generated with two-cycle amplification protocols. We have shown that the Affymetrix IVT-E labelling protocol produces data with less associated bias than the two-cycle protocol, and as such, would recommend this kit for new experiments that involve small samples.

\section{Background}

Over the past fifteen years microarray technology has revolutionised molecular biology. Where once determination of quantitative expression levels of genes involved performing Northern blot analyses, microarrays have made possible the investigation of the expression level of thousands of genes in a single experiment [1,2]. In recent years the cost of performing microarray experiments has decreased dramatically, as has the quantity of RNA required. Early experiments to analyse global gene expression profiles in Arabidopsis research involved

\footnotetext{
* Correspondence: tara.holman@nottingham.ac.uk

† Contributed equally

${ }^{1}$ Centre for Plant Integrative Biology, University of Nottingham, Nottingham, LE12 5RD, UK
}

(c) 2010 Holman et al; licensee BioMed Central Ltd. This is an Open Access article distributed under the terms of the Creative Commons Attribution License (http://creativecommons.org/licenses/by/2.0), which permits unrestricted use, distribution, and reproduction in any medium, provided the original work is properly cited.

using large quantities of tissue in order to generate the required amount of RNA. For example, Schaffer et al. [3] required $1 \mathrm{~g}$ of fresh tissue to extract $100 \mu \mathrm{g}$ RNA to use with a cDNA spotted array; Affymetrix currently recommends using as little as $50 \mathrm{ng}$ total RNA for labelling with the ATH1 expression array http://www.affymetrix.com. The reduction in the quantity of material required has led to an increasing focus on the analysis of less abundant tissues, subsets of cells or even individual cells, isolated using techniques such as laser microdissection and fluorescence-activated cell sorting [4-10]. At present, it is not possible to extract sufficient RNA from micro-dissected samples for transcriptomic analysis, so various methods of RNA amplification have been developed and implemented [11-14]. 
For transcriptomic analyses, extracted RNA must be labelled prior to hybridisation to the array. Standard protocols (one-cycle labelling), such as the Affymetrix One-Cycle Eukaryotic Target Labelling Assay and a new protocol suitable for small samples, the Affymetrix GeneChip 3' IVT-Express Kit (IVT-E), use oligo(dT) primers with a T7 recognition site to reverse transcribe mRNA to cDNA. DNA polymerase is used for the production of double stranded cDNA. T7 RNA polymerase, in the presence of biotinylated nucleotides, is used for in vitro transcription (IVT) of biotinylated cRNA, which is hybridised to the array. Small sample protocols follow a similar methodology, but the initial IVT step uses unlabeled nucleotides. Using random primers, the mRNA is reverse transcribed, followed by amplification using the oligo(dT)-T7 primer. The second IVT uses T7 RNA polymerase to incorporate biotinylated nucleotides into the mRNA.

Several commercial kits are available for producing two-cycle amplified samples for hybridisation to microarrays, for example the Two-Cycle Eukaryotic Target Labelling Assay (Affymetrix, High Wycombe, UK), the Microarray Target Amplification Kit (Roche Diagnostics Ltd. Burgess Hill, UK), the MessageAmp aRNA Amplification Kit (Ambion, Texas, USA), and the FL-Ovation Biotin System (Nugen Technologies, California, USA). Results produced using various commercial kits have been analysed using human samples, and it was shown that the Affymetrix amplification system showed the highest correlation to the standard one-cycle protocol [15].

The Affymetrix ATH1 microarray (Affymetrix UK Ltd., High Wycombe, UK) is frequently used for Arabidopsis transcriptomic analyses. The array consists of 22759 gene-specific probe sets, each containing eleven perfect match (PM) and eleven mis-matched (MM) probes (twenty-five base oligonucleotides hybridised to a glass slide). PM probes are complementary to the mRNA sequence; MM probes differ from the PM probes only at nucleotide thirteen, where the base is swapped to its complementary partner (e.g. C to G, A to $\mathrm{T}$ etc.). The array represents 22543 individual Arabidopsis loci (The Arabidopsis Information Resource release 8 (TAIR 8)), with some loci represented by more than one probe set. Following recent updates to the Arabidopsis annotated genome, it has been found that up to 10,000 loci may not be represented on the array (TAIR8), thus the ATH1 array has genomic coverage of approximately $70 \%$.

Two-cycle sample labelling protocols have been used with the Affymetrix Arabidopsis ATH1 microarray in many experiments [4,16-20]. Whilst an evaluation of the effects of amplification has been carried out for plant samples with two-colour arrays [21], a direct comparison of one- and two-cycle labelled samples has not been published for the Affymetrix ATH1 microarray. This is despite investigations showing that sample amplification causes errors when using the Affymetrix human HG-U133A array [22,23].

Here we describe the analysis of gene expression data generated using Affymetrix one- and two-cycle and IVT-E labelling protocols with the ATH1 microarray. We show that all protocols yield similar results in terms of relative levels of gene expression. There is, however, a subset of genes that are consistently mis-represented by the two-cycle process. We show that two-cycle labelling is an acceptable method for generating samples for use with the Affymetrix ATH1 microarray in situations when enough material cannot reasonably be generated otherwise. However, data relating to the loci highlighted in this report should be treated with caution. Based on the analyses presented here, we recommend the use of the Affymetrix IVT-E labelling protocol for small samples.

\section{Results}

RNA was isolated from 7-day-old Arabidopsis wild-type (Col-0) roots dissected into two sections, the meristem (MS) and elongation zone (EZ). The MS, the region of the root where cell division occurs, is approximately 350 $\mu \mathrm{m}$ in length and extends from the tip of the root to the top of the lateral root cap. The EZ extends from the top of the MS to the first root hair bulge, and is where the cells are rapidly expanding in length. The EZ is approximately $850 \mu \mathrm{m}$ in length. An Arabidopsis root is around $100 \mu \mathrm{m}$ in diameter after 7-days development, thus around 365 roots would need to be dissected in to obtain $1 \mathrm{~mm}^{3}$ of material.

For these experiments, three biological replicates from separate pools of seed were used, resulting in six RNA samples (three MS replicates and three EZ replicates). An aliquot of RNA of each sample was diluted to a con-

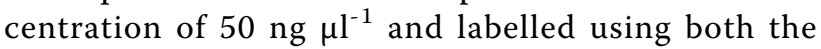
Affymetrix two-cycle labelling protocol and the Affymetrix IVT-E protocol. One microgram of total RNA was labelled using the Affymetrix one-cycle labelling protocol. A total of eighteen data sets were produced from the original six RNA extractions, with three replicates each of MS one-cycle, MS two-cycle, MS IVT-E, EZ one-cycle, EZ two-cycle and EZ IVT-E. These labelled samples were hybridised to the Affymetrix ATH1 gene expression array.

\section{Correlation between replicates and between protocols}

To investigate the reproducibility of the microarray data, replicates were analysed pair-wise for consistency. The $\mathrm{R}^{2}$ value of $\log _{2}$ data ranged from 0.973 to 0.993 , showing a large degree of correlation between replicates 
(Additional file 1). Principal Component Analysis (PCA) was used to show the global differences between the samples. The resulting plot showed that the three replicates from each labelling technique were highly similar, and that the IVT-E and one-cycle data sets were more similar to each other than either were to the two-cycle data (for both MS and EZ tissues) (Figure 1). The first principal component represented the differences between the MS and EZ tissues, whereas the second principal component represents differences between the one-cycle/IVT-E versus two-cycle protocols. To further investigate the differences in labelling protocol, $R^{2}$ values of pair-wise comparisons of the three protocols for each of the replicates showed that the two-cycle

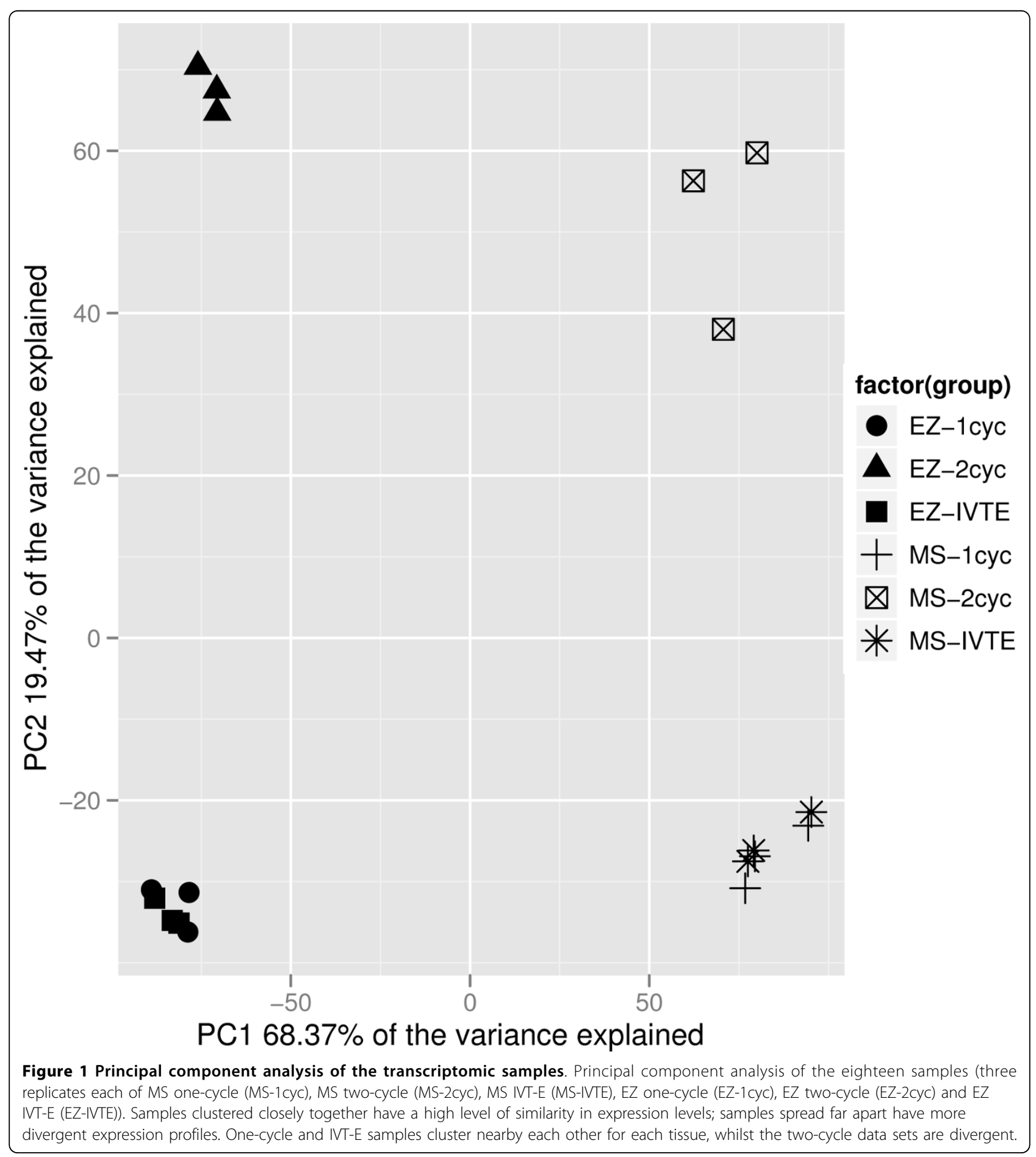


Table 1 Statistical comparison of the biological replicates

\begin{tabular}{clcccc}
\hline Region & \multicolumn{1}{c}{ Comparison } & Rep 1 & Rep 2 & Rep 3 & Average \\
\hline MS & 1-cycle vs. 2-cycle & 0.948 & 0.948 & 0.938 & 0.945 \\
MS & 2-cycle vs. IVT-E & 0.947 & 0.953 & 0.941 & 0.947 \\
MS & 1-cycle vs. IVT-E & 0.980 & 0.980 & 0.977 & 0.979 \\
\hline EZ & 1-cycle vs. 2-cycle & 0.939 & 0.934 & 0.935 & 0.936 \\
EZ & 2-cycle vs. IVT-E & 0.936 & 0.932 & 0.931 & 0.933 \\
EZ & 1-cycle vs. IVT-E & 0.981 & 0.981 & 0.975 & 0.979 \\
\hline MS & Pairwise one-cycle & - & - & - & 0.985 \\
MS & Pairwise two-cycle & - & - & - & 0.978 \\
MS & Pairwise IVT-E & - & - & - & 0.981 \\
\hline EZ & Pairwise one-cycle & - & - & - & 0.991 \\
EZ & Pairwise two-cycle & - & - & - & 0.982 \\
EZ & Pairwise IVT-E & - & - & - & 0.989 \\
\hline
\end{tabular}

The top half of the table shows the $R^{2}$ values for the comparisons for each of the three biological replicates (Rep 1-3) of meristem (MS) and elongation zone (EZ) tissues with the three labelling protocols. The bottom half of the table shows the average $R^{2}$ values of the pairwise replicate comparisons for each labelling protocol (i.e. the average of rep1 vs. rep2, rep1 vs. rep3 and rep 2 vs. rep3).

protocol produced data that was less similar to the onecycle and IVT-E data sets $\left(\mathrm{R}^{2}\right.$ values between 0.9312 and 0.9532), than the one-cycle and IVT-E data sets were to each other $\left(R^{2}\right.$ values between 0.9751 and 0.981) (Table 1). This implies that there is a reduced linearity in the relationship between the low RNA concentration samples and total RNA samples when the IVT-E protocol is used rather than the two-cycle protocol.

\section{$5^{\prime}$ or $3^{\prime}$ bias caused by amplification}

To determine if there was a differential bias in hybridisation for probes towards either the 5' or 3' ends of the gene caused by the different labelling protocols, the level of hybridisation at individual probes on the array were examined. It was expected that incomplete IVT would cause a 3' probe bias (increased hybridisation levels at probes nearest the 3 ' end of the gene), and a large amount of cRNA degradation would lead to a bias towards 5' probe expression.

The eleven PM probes in a probe-set were numbered from 1 (nearest the $5^{\prime}$ end of the mRNA) to 11 (nearest the 3' end of the mRNA). For each probe-set, the median of the $\log _{2}$ expression levels on probes 1 to 5 and the median of the $\log _{2}$ expression levels on probes 7 to 11 were calculated. The difference between these values gives a measure of the degree of $5^{\prime}$ bias for that gene, with positive numbers indicating 5 ' bias and negative numbers indicating 3' bias.

For all of the labelling protocols, there is evidence of some degree of 3' bias (i.e. the averages of the distributions are to the left of zero), and this 3' bias was more pronounced in data from the two-cycle protocol for both the MS and EZ tissues (Figure 2). The values corresponding to the two-cycle protocol are more negative than the one-cycle and IVT-E mean scores, indicating an increased level of bias.

To further investigate the phenomenon of increased 3' bias in the two-cycle data, we used quantile plots. Analysis of the results showed that the two-cycle protocol introduced a marked increase in 3' bias in comparison to the one-cycle and IVT-E protocols (Additional file 2). There was a slight increase in 3' bias in the IVT-E data in comparison to the one-cycle data, but the difference was much less than for the two-cycle data.

\section{Differentially expressed loci between the labelling protocols}

Linear models of $\log _{2}$ expression levels were fitted pairwise for data generated using the one-cycle, two-cycle and IVT-E protocols. The studentised residuals were used to assess which of the loci showed differential expression between two protocols. For such a large number of degrees of freedom, the studentised residuals follow a standard Normal distribution. We set a threshold of 3.5 for the residuals (corresponding to 3.5 standard deviations from the mean, and covering $99.95 \%$ of data points), classifying those loci with a residual greater than 3.5 as over-amplified and those with a residual less than -3.5 as under-amplified.

As a consequence of the data having a standard Normal distribution, we would expect only 10 of the 22543 loci to have a studentised residual with an absolute value greater than 3.5. We observe in the order of 100 loci with absolute residual values greater than 3.5 for each of the tissues (Table 2 and Additional file 3 ).

To define a probe-set as 'mis-amplified' we used the criterion that it must be either classed as over- or underamplified in at least two of the three replicates, and in both the one-cycle vs. two-cycle and IVT-E vs. twocycle lists. We found 9 loci that were over-amplified by the two-cycle protocol, and 26 genes under-amplified by the two-cycle protocol (Additional file 4).

For the loci classed as over-amplified by the two-cycle method, the median RMA expression levels were 34 for the one-cycle, 26 for the IVT-E and 385 for the twocycle. All of the genes had expression values below 250 in the one-cycle and IVT-E data. They can therefore be classed as low expressers (Additional file 5).

Loci classed as under-amplified had median RMA expression values of 417 in the one-cycle data, 404 in the IVT-E data and 62 in the two-cycle data. 16 of the 26 genes had expression values of over 500 in the one-cycle data of either the MS or EZ tissues. The under-amplified genes are generally medium to high expressers, although there are a few genes with low levels of expression in the list (Additional file 5). 


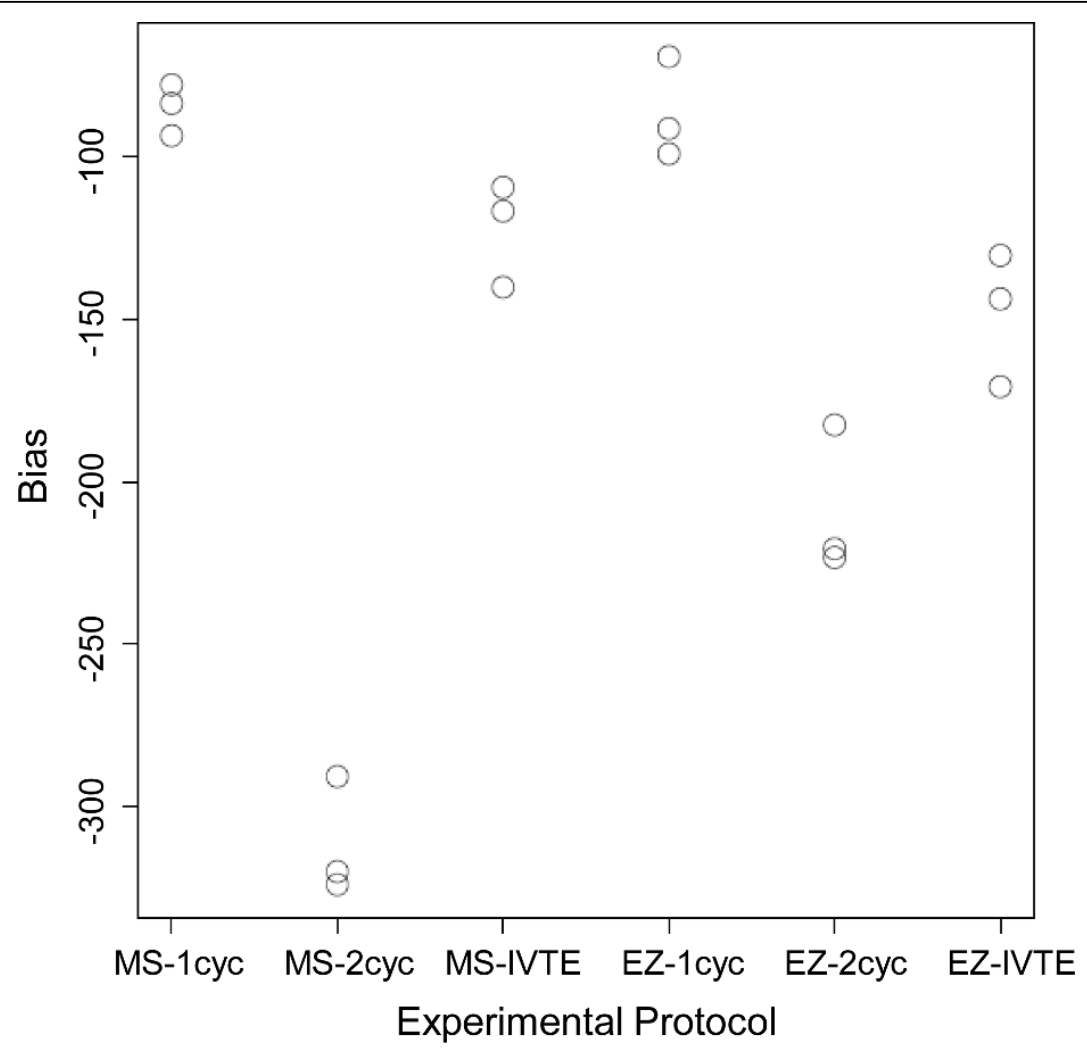

Figure 2 Mean bias statistics for the three protocols. Mean bias statistics for the three protocols across the MS and EZ zones and three replicates. More negative numbers indicate increased bias.

Table 2 The number of over- and under-amplified probes

\begin{tabular}{lllllllll}
\hline & & \multicolumn{2}{l}{ Number over-amplified loci } & \multicolumn{2}{c}{ Number under-amplified loci } \\
Region & Comparison & Rep 1 & Rep 2 & Rep 3 & Rep 1 & Rep 2 & Rep 3 \\
\hline MS & 1-cyc vs. 2-cyc & 35 & 20 & 32 & 143 & 148 & 127 \\
MS & IVT-E vs. 2-cyc & 37 & 16 & 32 & 87 & 127 & 94 \\
\hline EZ & 1-cyc vs. 2-cyc & 39 & 46 & 39 & 119 & 107 & 112 \\
EZ & IVT-E vs. 2-cyc & 38 & 42 & 35 & 101 & 85 & 93 \\
\hline
\end{tabular}

The number of over- and under-amplified loci for pair-wise comparisons of two-cycle vs. one-cycle and IVT-E protocols for the three replicates (Rep 1-3).

\section{The expression levels of mis-amplified loci in other} publically available data sets

To determine whether the mis-amplification of specific probe-sets is a general phenomenon, the expression levels of the genes presented in Additional file 4 were analysed in publicly available Arabidopsis root data sets $[24,25]$. These data sets were selected because the biological experiments most closely match the experiment presented here. Whilst there were lab-to-lab variations in the experimental conditions, all the compared samples were generated from Col-0 WT roots. The experiments presented by Stepanova et al. [24] compared WT, aux 1-7 and ein2-5 roots exposed to either air or ethylene, or with and without auxin treatment. The 'air-treated' WT sample in the ethylene experiment and the 'mock WT' in the auxin experiment were used for comparison with our data sets. The Vanneste et al. [25] experiments compared gene expression in WT and $\operatorname{sir} 1$ roots after temporal application of $\alpha$-naphthaleneacetic acid (NAA). For comparison with our data, we used the data generated from WT roots with no NAA application. Data from MS and EZ tissues was averaged to give an expression level for the one-cycle, two-cycle and IVT-E data for root tips.

To allow for the variance in hybridisation levels in each experiment, median expression values on each array were calculated. The expression of each gene on the array was divided by the median expression value for that array to give a -ised expression value to use for comparison between chips. The results showed that 
genes in the over-amplified list were on average 19.7 fold higher in the two-cycle data compared to one-cycle or IVT-E data (10.6 fold (SE 2.8) in the Vanneste data, 20.7 fold (SE 5.4) in Stepanova WT 'air' data set, 23.8 fold (SE 6.6) in Stepanova WT 'mock' data set, 16.4 fold (SE 3.8) compared to the one-cycle root tip data and 27.2 fold (SE 6.4) compared to the IVT-E root tip data). Genes identified as under-amplified were, on average, 6.3 fold lower in the two-cycle data set than the other experiments (5.2 fold (SE 1.4) in the Vanneste data, 6.5 fold (SE 1.5) in Stepanova WT 'air', 5.8 fold (SE 1.0) in Stepanova WT 'mock', 7.2 fold (SE 0.5) compared to the one-cycle root tip data and 6.6 fold compared to the IVT-E root tip data) (Additional file 6).

At present, there are no public IVT-E data sets available for Arabidopsis root tissue. Therefore in order to further investigate the mis-amplified probes, the expression of the loci were analysed in publicly available data sets which have utilised two-cycle amplification and compared with data of similar tissue types that have used the one-cycle protocol. Root tissues were analysed by comparing average expression across the root sections presented by Birnbaum et al. [4], with the values from the wild-type control samples produced by Stepanova et al. [24] (two-cycle and one-cycle labelled samples respectively).

Genes classed as under-amplified were expressed an average of 5.4 fold (SE 1.5) lower in two-cycle amplified root tissue compared to the one-cycle samples (Additional file 7). Of the 26 loci classed as under-amplified, 25 were expressed over 1.5 fold lower in two- vs. onecycle root tissue (Table 3). Genes classed as over-amplified were expressed an average of 2.1 fold (SE 0.3) higher in two-cycle root tissues compared to one-cycle labelled samples (Additional file 6). 8 of the 9 genes in the list were expressed over 1.5 fold higher in the two-cycle root data compared to the one-cycle data (Table 3).

\section{The effect of two-cycle amplification on the identification of potentially differentially regulated genes}

Transcriptomic analyses usually result in the production of lists of genes showing expression changes between samples. These genes are then carried forward for postgenomic analyses, for example, through the analysis of knockout or over-expression lines, or visualisation of expression using reporter constructs.

To give an indication of the effect of the different labelling protocols on representation within gene lists, loci that were differentially expressed (DE) between MS and EZ tissues were identified. There were 6117 genes that were classed as DE using the one-cycle data, 5459 genes using the two-cycle data, and 6200 genes using the IVT-E data. 4459 loci were classed as DE with all three protocols $(73 \%$ of the one-cycle DE genes, $82 \%$ of two-cycle DE genes, $72 \%$ of the IVT-E DE genes) (Figure 3). Whilst there is a large amount of overlap between the gene lists, this shows that the different labelling protocols have had an effect on the results generated from the experiment, and may lead to altered biological interpretation.

\section{Bioinformatics analysis of the reason for the mis- amplified probes}

In order to investigate the discrepancy in signal between the two-cycle and other protocols for these probesets, several approaches were employed. The first of these was probe-remapping [26], wherein the individual probes for each probeset are re-BLASTED into the current reference build of the Arabidopsis genome held in GenBank. The probe sequences for the ATH1 array were determined in 2001 and in the intervening years continued sequencing and mapping projects have refined and corrected the layout of the genome, the net effect of which is that 11338 probes (4.7\%) have moved around the genome and should be associated with other probesets or indeed not included at all. Our hypothesis was that the discrepant genes were biased in the content for probes which were probing for multiple loci, for no loci at all or were otherwise incorrect, leading to a bias in their signals which led to them being more susceptible to amplification effects. Using a remapped chip definition file and reprocessing the data showed that the biases were unaffected by this reanalysis.

A second approach was to examine whether the gene sequences were more or less susceptible to transcriptional and therefore amplificational biases due to selfhybridisation effects. Simple sequence features include high GC content, which would result in higher melting temperatures and potentially reduced transcription rates, and the presence of quadruplexes, which are known to inhibit the progress of complexes along nucleic acids strands [27]. By comparing the sequences of the list of misamplified genes with a randomised selection from the rest of the genome no significant overrepresenation of either GC rich or quadruplex regions was observed.

\section{Discussion}

Transcriptomic analyses have been extensively used within plant sciences in recent years [2,28-33]. Until recently the technique has required a large amount of starting material. This has meant that analysis of small biological samples was prohibited. Two-cycle amplification has allowed small samples to be analysed using microarrays, and has shown that a powerful extra dimension can be added to knowledge by studying only a small subset of cells (for example, [4,7]). Affymetrix has recently introduced the IVT-Express labelling protocol, which can handle both large and small samples. 
Table 3 The over- and under-amplified loci.

\begin{tabular}{|c|c|c|c|c|c|}
\hline Probe ID & $\begin{array}{l}\text { current 1- } \\
\text { cyc vs. 2- } \\
\text { cyc }\end{array}$ & $\begin{array}{l}\text { current IVT- } \\
\text { E vs. 2-cyc }\end{array}$ & $\begin{array}{c}\text { Stepanova } \\
\text { vs. Birnbaum }\end{array}$ & AGI code & Description \\
\hline 247762_at & 16.4 & 39.8 & 2.4 & AT5G59170 & Proline-rich family protein. \\
\hline 249552_s_at & 19.7 & 25.9 & 1.8 & $\begin{array}{l}\text { AT5G38250 } \\
\text { AT5G38240 }\end{array}$ & $\begin{array}{l}\text { AT5G38250, serine/threonine protein kinase, putative; AT5G38240, serine/ } \\
\text { threonine protein kinase, putative. }\end{array}$ \\
\hline 251127_at & 3.4 & 8.3 & 2.1 & AT5G01080 & Beta-galactosidase. \\
\hline 252971_at & 10.9 & 22.5 & 1.6 & AT4G38770 & PRP4 (PROLINE-RICH PROTEIN 4). \\
\hline 255138_at & 12.5 & 14.2 & 1.8 & AT4G08380 & Proline-rich extensin-like family protein. \\
\hline 262566_at & 28.2 & 63.1 & 3.0 & AT1G34310 & ARF12 (AUXIN RESPONSE FACTOR 12); transcription factor. \\
\hline 266152_s_at & 14.3 & 17.2 & 2.8 & $\begin{array}{l}\text { AT3G31908 } \\
\text { AT3G32377 } \\
\text { AT2G12050 }\end{array}$ & $\begin{array}{l}\text { AT3G31908, pseudogene, similar to aintegumenta-like protein; } \\
\text { AT3G32377, pseudogene, similar to aintegumenta-like protein; } \\
\text { AT2G12050, pseudogene, embryogenesis protein-related, similar to BABY } \\
\text { BOOM (A. thaliana). }\end{array}$ \\
\hline 266154_at & 39.1 & 47.1 & 3.0 & AT2G12190 & Cytochrome P450, putative. \\
\hline 245513_at & 4.4 & 4.0 & 3.2 & AT4G15780 & $\begin{array}{l}\text { ATVAMP724 (Arabidopsis thaliana vesicle-associated membrane protein } \\
\text { 724). }\end{array}$ \\
\hline 245665_at & 4.8 & 5.1 & 2.4 & AT1G28250 & $\begin{array}{l}\text { Similar to hypothetical protein [Oryza sativa (japonica cultivar-group)] (GB: } \\
\text { BAC84779.1). }\end{array}$ \\
\hline 246210_at & 8.0 & 6.9 & 2.3 & AT4G36420 & Ribosomal protein L12 family protein. \\
\hline 249583_at & 5.4 & 5.8 & 1.8 & AT5G37770 & TCH2 (TOUCH 2); calcium ion binding. \\
\hline 250226_at & 7.4 & 6.6 & 3.6 & AT5G13780 & GCN5-related N-acetyltransferase, putative. \\
\hline 250935_at & 9.0 & 8.9 & 39.7 & AT5G03240 & UBQ3 (POLYUBIQUITIN 3); protein binding. \\
\hline 253189_at & 8.3 & 6.0 & 5.8 & no_match & No_match. \\
\hline 253464_at & 6.8 & 4.7 & 3.4 & AT4G32030 & Unknown protein. \\
\hline 253545_at & 5.4 & 7.4 & 4.0 & AT4G31310 & $\begin{array}{l}\text { Avirulence-responsive protein-related/avirulence induced gene (AIG) } \\
\text { protein-related. }\end{array}$ \\
\hline 256092_at & 9.8 & 12.4 & 8.3 & AT1G20696 & HMGB3 (HIGH MOBILITY GROUP B 3); transcription factor. \\
\hline 256231_at & 9.4 & 9.5 & 5.3 & AT3G12630 & Zinc finger (AN1-like) family protein. \\
\hline 258001_at & 5.5 & 6.2 & 9.8 & AT3G28950 & $\begin{array}{l}\text { Avirulence-responsive protein-related/avirulence induced gene (AIG) } \\
\text { protein-related. }\end{array}$ \\
\hline 258397_at & 6.1 & 6.1 & 1.9 & AT3G15357 & Unknown protein. \\
\hline 258958_at & 7.0 & 10.4 & 4.6 & AT3G01390 & VMA10 (VACUOLAR MEMBRANE ATPASE 10). \\
\hline 259095_at & 5.9 & 6.2 & 1.7 & AT3G05020 & ACP1 (ACYL CARRIER PROTEIN 1). \\
\hline 262295_at & 7.7 & 4.9 & 4.4 & AT1G27650 & ATU2AF35A; RNA binding. \\
\hline 263878_s_at & 4.7 & 4.4 & 3.8 & $\begin{array}{l}\text { AT3G18140 } \\
\text { AT2G22040 }\end{array}$ & $\begin{array}{l}\text { AT3G18140, transducin family protein/WD-40 repeat family protein; } \\
\text { AT2G22040, transducin family protein/WD-40 repeat family protein. }\end{array}$ \\
\hline 264566_at & 6.8 & 4.6 & 5.6 & AT1G05270 & TraB family protein. \\
\hline 264702_at & 5.3 & 5.3 & 3.0 & AT1G70190 & Ribosomal protein L12 family protein. \\
\hline 265103_at & 12.9 & 4.2 & 3.9 & AT1G31070 & UDP-N-acetylglucosamine pyrophosphorylase-related. \\
\hline 265443_at & 6.4 & 6.7 & 3.0 & AT2G20750 & ATEXPB1 (ARABIDOPSIS THALIANA EXPANSIN B1). \\
\hline 266074_at & 5.1 & 8.1 & 1.7 & AT2G18740 & $\begin{array}{l}\text { Small nuclear ribonucleoprotein } E \text {, putative/snRNP-E, putative/Sm protein } \\
E \text {, putative. }\end{array}$ \\
\hline 266125_at & 6.9 & 6.3 & 1.8 & AT2G45050 & Zinc finger (GATA type) family protein. \\
\hline 267064_at & 6.8 & 7.9 & 2.9 & AT2G41110 & CAM2 (CALMODULIN-2); calcium ion binding. \\
\hline $\begin{array}{l}\text { AFFX-Athal- } \\
\text { GAPDH_5_s_at }\end{array}$ & 13.4 & 8.3 & 11.8 & AT3G04120 & $\begin{array}{l}\text { GAPC (GLYCERALDEHYDE-3-PHOSPHATE DEHYDROGENASE C SUBUNIT); } \\
\text { glyceraldehyde-3-phosphate dehydrogenase. }\end{array}$ \\
\hline
\end{tabular}

Loci classed as over- (above the break line) and under-amplified (below the break line) in both the data from this study and in independent one-cycle vs. twocycle root data sets. Numbers represent the fold change in the comparison. Where several AGI codes are given for a particular probe ID, more than one transcript is likely to hybridise to the probes

Whilst various two-cycle labelling protocols have been compared $[21,22,34]$, it has not previously been shown what the effect of two-cycle amplification would have on the representation of plant gene expression in Affymetrix microarray experiments.
We have shown that the Affymetrix one- and twocycle and IVT-E labelling protocols do not have large effects on the observed gene expression. Lists of DE genes between our two tissue samples were shown to have a large degree of correlation using the one-cycle, 


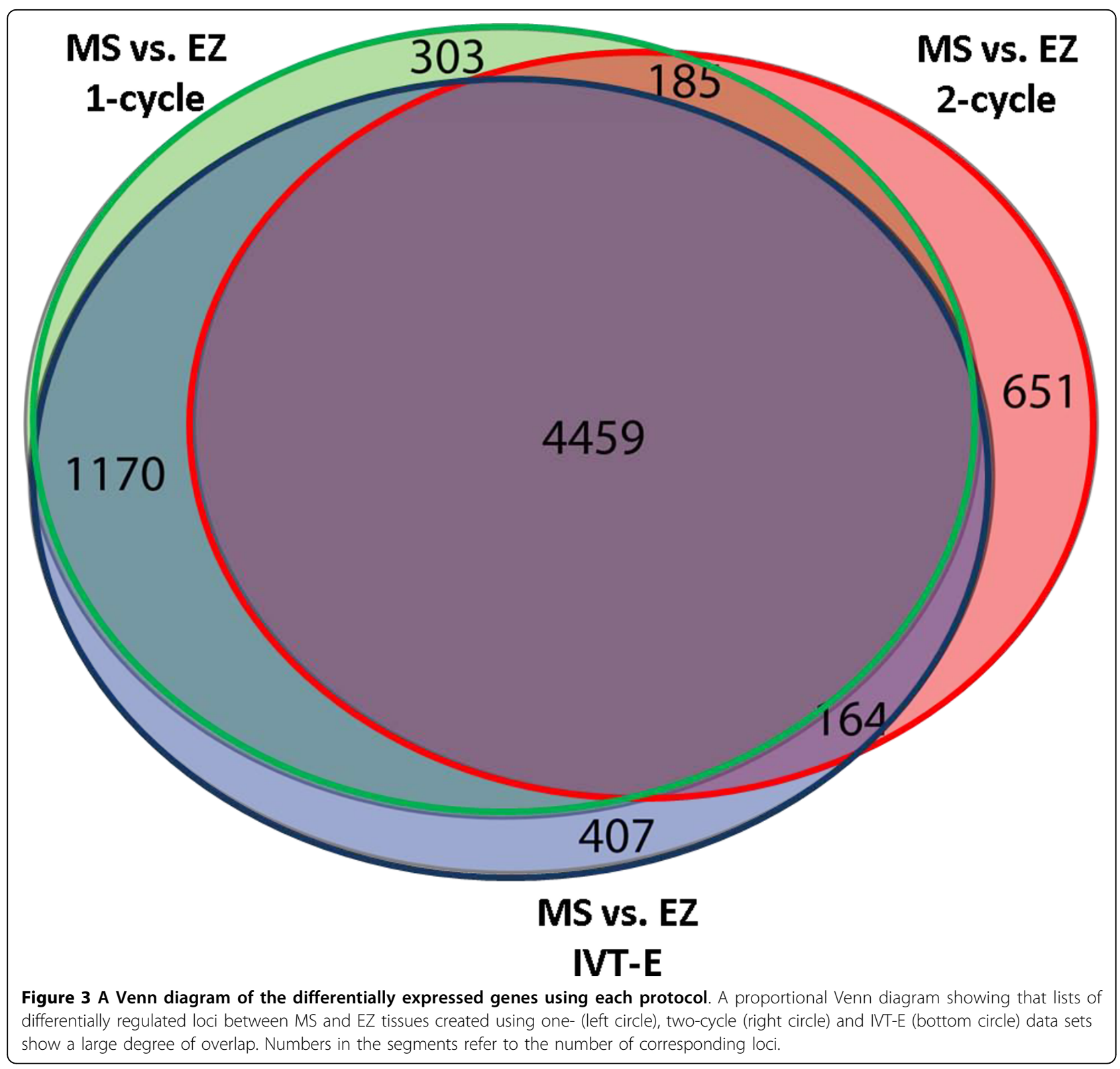

two-cycle or IVT-E datasets. The lists, however, were not identical. We have shown that there are a small number of loci that are consistently under- or overrepresented on the array after the two-cycle labelling process. There is no obvious mechanistic effect for the misrepresentation of these loci.

It is important to note that many of the probes we have identified as unreliable in two-cycle data relate to genes of biological interest. Included in the lists are at least three genes that encode transcription factors (two zinc-finger proteins and a WD40 repeat family protein), three genes which relate to cellular structural changes (a beta-galactosidase, an extensin and an expansin), and two genes that function in calcium ion binding. An important auxin-related gene is included in the lists (ARF12), highlighting the need for extra caution when looking for responses to auxin with two-cycle data. Of the 33 genes in Additional file 6 and 7, only two are classified as encoding 'unknown proteins' and one has 'no match' to the TAIR 8 genome sequence.

Whilst the lists of loci shown to be mis-represented in different gene lists following two-cycle amplification indicate that data associated with these loci should be treated as uncertain, this list is unlikely to be exhaustive. The data presented here are generated from Arabidopsis root tissue, and we are unable to comment on the behaviour of loci not expressed in our experiments. Therefore, it is likely that there are other probes that have a 
tendency to be under- or over-amplified using two-cycle labelling.

\section{Conclusions}

We have shown here that two-cycle amplification is an acceptable method of producing transcriptomic data with the Affymetrix ATH1 microarray. One should, however, be as cautious of the differences in the labelling protocols between one- and two-cycle and IVT-E data sets as one would be with any aspect of the transcriptomic workflow [35-38], and refrain from the comparison of absolute expression levels of loci from different protocols. Based on the results presented here, we recommend that extreme caution be placed on the expression level of the highlighted loci when using data sets produced using a two-cycle process. We have found that the Affymetrix IVT-E labelling protocol produces data with less bias than the two-cycle protocol, and as such, would recommend this kit for new experiments that involve small samples.

\section{Methods}

\section{Biological material}

Wild-type Col-0 seedlings were grown vertically on $1 / 2$ MS media [39] supplemented with 1\% (w/v) PGP-type agarose (Park Scientific Ltd., UK) for seven days in controlled environmental conditions of $24^{\circ} \mathrm{C}$, continuous light of $150 \mu \mathrm{mol} \mathrm{m}^{-1} \mathrm{~s}^{-1}$. For each biological replicate, approximately 600 roots were dissected into the meristem (MS) (from the root tip to the top of the lateral root cap, approximately $350 \mu \mathrm{m}$ from the root tip) and the rapid elongation zone (EZ) (from the top of the lateral root cap to the first visible root hair bulge, approximately $850 \mu \mathrm{m}$ from the top of the lateral root cap). Dissected samples were immediately frozen in liquid nitrogen. Three biological replicates from separate pools of seeds were used. Plants for seed propagation were grown simultaneous in controlled conditions with a 16 h light $\left(23^{\circ} \mathrm{C}\right), 8 \mathrm{~h}$ dark $\left(18^{\circ} \mathrm{C}\right)$ cycle.

\section{RNA extraction and dilution}

RNA was extracted using the Qiagen MicroRNA Kit following the manufacturers recommended protocol (Qiagen, Crawley, UK). RNA was quantified using a Nanodrop ND100 spectrophotometer (Nanodrop, Wilimington, USA). All RNA samples were approximately 1 $\mu \mathrm{g} / \mu \mathrm{l}$ in a total volume of $10 \mu \mathrm{l}$. For the two-cycle and IVT-E samples, RNA was diluted with RNase-free water to make a final concentration of $50 \mathrm{ng} / \mu \mathrm{l}$ (equivalent to 30 dissected root sections).

\section{Amplification and labelling}

Labelling of RNA samples was conducted using the Affymetrix One- and Two-Cycle Eukaryotic Target
Labelling Assay kits following standard Affymetrix protocols (Affymetrix UK Ltd., High Wycombe, UK). RNA labelling and hybridisation to Affymetrix ATH1 arrays were performed by the Nottingham Arabidopsis Stock Centre (NASC).

\section{Data analysis}

Data were normalised from .cel files using the RMA protocol within R/Bioconductor [40]. Further analyses were performed using Excel 2007 (Microsoft Corporation, Redmond, USA). Comparisons to publicly available data used only wild-type, untreated data sets. Where experiments also contained mutant alleles or hormone treatments, these arrays were excluded from the comparisons. Differentially regulated loci had a fold change greater than 2, and a Benjamini and Hochberg False Discovery Rate of 0.05 (or 5\%) [41].

\section{Accession numbers}

Data produced in these experiments have been made available from Arrayexpress http://www.ebi.ac.uk/ arrayexpress/ with accession number [E-MEXP-2608]. Other data sets used in this manuscript were obtained from GEO http://www.ncbi.nlm.nih.gov/geo/ with the accession numbers: [GEO: GSE5749] [4], [GEO: GSE432] [24] and [GEO: GSE3350] [25].

\footnotetext{
Additional file 1: Pairwise comparisons of MS and EZ samples using the three different protocols. Pair-wise comparisons of biological replicates of Log2 data in the meristem (MS, left panels) and elongation zone (EZ, right panels) tissues using the three different labelling protocols - A. 1-cycle; B. 2-cycle; C. IVT-E. R ${ }^{2}$ values are indicated in each comparison.

Click here for file

[ http://www.biomedcentral.com/content/supplementary/1746-4811-6-9S1.DOC]

Additional file 2: Quantile plots to investigate $\mathbf{5}^{\prime}$ and $\mathbf{3}^{\prime}$ bias. For a given probability $q$ between 0 and 1 , the $q$-quantile of a data vector is the value $c_{q}$, such that the proportion of the observations less than $c_{q}$ is equal to $q$. For example, the median is the 0.5 -quantile. Some of the biases are very large, so we trim the bias observation vectors and only consider the quantiles between 0.05 and 0.95 . These plots are shown above. From the plots, it is clear that the $3^{\prime}$ bias is significantly higher for the 2-cycle data. This can be seen by the fact that in both of the plots in the figure, the red lines (representing the two-cycle labelling protocol) are lower than either the black or blue lines (one-cycle and IVT-E protocols). The IVT-E protocol shows marginally more $3^{\prime}$ bias than the one-cycle protocol, but this is much less marked a difference than in the case of the two-cycle protocol.

Click here for file

[http://www.biomedcentral.com/content/supplementary/1746-4811-6-9S2.PDF ]

Additional file 3: Loci with absolute residual values greater than 3.5 in pairwise comparisons. A table showing the ID numbers of probes sets classed as mis-amplified (absolute residual values greater than 3.5) in pairwise comparisons samples using different labelling techniques. The numbers of loci in each list are shown also in Table 2.

Click here for file

[http://www.biomedcentral.com/content/supplementary/1746-4811-6-9S3.XLS ]
} 
Additional file 4: Loci classed as mis-amplified. A table showing the loci that have been classed as mis-amplified, along with the fold change of the mis-amplification (1-cycle vs. 2-cycle data) for MS and EZ tissues, AGI codes and locus descriptions. Positive fold changes indicate overamplification, negative fold changes indicate under-amplification.

Click here for file

[http://www.biomedcentral.com/content/supplementary/1746-4811-6-9S4.DOC]

Additional file 5: RMA expression values of mis-amplified probes The RMA normalised expression values of loci identified as mis-amplified in Table 3. Numbers refer to the expression level in the one-cycle, 2-cycle and IVT-E data sets of MS and EZ tissues.

Click here for file

[http://www.biomedcentral.com/content/supplementary/1746-4811-6-9S5.DOC ]

Additional file 6: Relative expression levels of the over- and underamplified probe sets. Relative expression levels (compared to median of the array) of the over- (above the break line) and under-amplified (below the break line) probe sets in other plant root data sets. Click here for file

[http://www.biomedcentral.com/content/supplementary/1746-4811-6-9S6.DOC]

Additional file 7: Relative expression level of probe IDs classed as over- and under-amplified in publicly available one- and two-cycle data sets. Relative expression level of probe IDs classed as over- (above the break line) and under-amplified (below the break line) in publicly available one- and two-cycle data sets (Stepanova et al. (2007) and Birnbaum et al. (2003) respectively).

Click here for file

[http://www.biomedcentral.com/content/supplementary/1746-4811-6-9S7.DOC]

\section{Acknowledgements}

We would like to thank Zoë Emmerson (NASC, University of Nottingham) for performing the RNA labelling and array hybridisations, and Sean May and Neil Graham (NASC) for their help with data analyses and statistical approaches. Jonathan Lawrence (Birmingham, UK) provided a Python script for dealing with the large data files generated as part of these experiments, Caroline Howells and Susana Ubeda-Tomas (CPIB, University of Nottingham) provided seeds and technical assistance. This work was funded through grant BB/D019613/1 from the BBSRC and EPSRC.

\section{Author details}

${ }^{1}$ Centre for Plant Integrative Biology, University of Nottingham, Nottingham, LE12 5RD, UK. ${ }^{2}$ School of Mathematical Sciences, University of Nottingham, Nottingham, NG7 2RD, UK. ${ }^{3}$ Department of Plant and Crop Sciences, School of Biosciences, University of Nottingham, Nottingham, LE12 5RD, UK.

\section{Authors' contributions}

$\mathrm{TJH}$ produced the material, generated and analysed the data, and wrote the manuscript. MHW carried out bioinformatic analyses and wrote the manuscript. KK produced the statistical analyses and wrote the manuscript. ILD helped with the statistical analyses and initial direction of the investigation. TCH provided ideas for bioinformatic analyses. ATAW helped with the statistical analyses and the direction for the manuscript. MJH conceived the idea for a manuscript and aided the direction of the analyses. All authors read and approved the final manuscript.

\section{Competing interests}

The authors declare that they have no competing interests.

Received: 11 November 2009 Accepted: 15 March 2010 Published: 15 March 2010

\section{References}

1. Lockhart DJ, Dong HL, Byrne MC, Follettie MT, Gallo MV, Chee MS, Mittmann M, Wang CW, Kobayashi M, Horton H, Brown EL: Expression monitoring by hybridization to high-density oligonucleotide arrays. Nature Biotechnology 1996, 14:1675-1680.

2. Schena M, Shalon D, Davis RW, Brown PO: Quantitative Monitoring of Gene-Expression Patterns with A Complementary-DNA Microarray. Science 1995, 270:467-470.

3. Schaffer R, Landgraf J, Accerbi M, Simon V, Larson M, Wisman E: Microarray analysis of diurnal and circadian-regulated genes in Arabidopsis. Plant Cell 2001, 13:113-123.

4. Birnbaum K, Shasha DE, Wang JY, Jung JW, Lambert GM, Galbraith DW, Benfey PN: A gene expression map of the Arabidopsis root. Science 2003, 302:1956-1960.

5. Spencer MWB, Casson SA, Lindsey K: Transcriptional profiling of the Arabidopsis embryo. Plant Physiology 2007, 143:924-940.

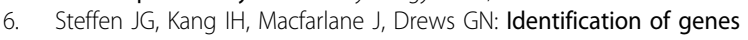
expressed in the Arabidopsis female gametophyte. Plant Journal 2007 51:281-292.

7. Casson S, Spencer M, Walker K, Lindsey K: Laser capture microdissection for the analysis of gene expression during embryogenesis of Arabidopsis. Plant Journal 2005, 42:111-123.

8. Inada N, Wildermuth MC: Novel tissue preparation method and cellspecific marker for laser microdissection of Arabidopsis mature leaf. Planta 2005, 221:9-16.

9. Brandt S, Kloska S, Altmann T, Kehr J: Using array hybridization to monitor gene expression at the single cell level. Journal of Experimental Botany 2002, 53:2315-2323.

10. Brandt S, Kehr J, Walz C, Imlau A, Willmitzer L, Fisahn J: A rapid method for detection of plant gene transcripts from single epidermal, mesophyll and companion cells of intact leaves. Plant Journal 1999, 20:245-250.

11. Baugh LR, Hill AA, Brown EL, Hunter CP: Quantitative analysis of mRNA amplification by in vitro transcription. Nucleic Acids Research 2001, 29:e29.

12. Nygaard V, Hovig E: Options available for profiling small samples: a review of sample amplification technology when combined with microarray profiling. Nucleic Acids Research 2006, 34:996-1014.

13. Wang E, Miller LD, Ohnmacht GA, Liu ET, Marincola FM: High-fidelity mRNA amplification for gene profiling. Nature Biotechnology 2000, 18:457-459.

14. Wang E: RNA amplification for successful gene profiling analysis. Journal of Translational Medicine 2005, 3.

15. Viale A, Li J, Tiesman J, Hester S, Massimi A, Griffin C, Grills G, Khitrov G, Lilley K, Knudtson K, Ward B, Kornacker K, Chu CY, Auer H, Brooks Al: Big results from small samples: evaluation of amplification protocols for gene expression profiling. J Biomol Tech 2007, 18:150-161.

16. Brady SM, Orlando DA, Lee JY, Wang JY, Koch J, Dinneny JR, Mace D, Ohler U, Benfey PN: A high-resolution root spatiotemporal map reveals dominant expression patterns. Science 2007, 318:801-806.

17. Cui HC, Levesque MP, Vernoux T, Jung JW, Paquette AJ, Gallagher KL, Wang JY, Blilou I, Scheres B, Benfey PN: An evolutionarily conserved mechanism delimiting SHR movement defines a single layer of endodermis in plants. Science 2007, 316:421-425.

18. Lee JY, Levesque M, Benfey PN: High-throughput RNA isolation technologies. New tools for high-resolution gene expression profiling in plant systems. Plant Physiology 2005, 138:585-590.

19. Nawy T, Lee JY, Colinas J, Wang JY, Thongrod SC, Malamy JE, Birnbaum K, Benfey PN: Transcriptional profile of the Arabidopsis root quiescent center. Plant Cell 2005, 17:1908-1925.

20. Penfield S, Li Y, Gilday AD, Graham S, Graham IA: Arabidopsis ABA INSENSITIVE4 regulates lipid mobilization in the embryo and reveals repression of seed germination by the endosperm. Plant Cell 2006, 18:1887-1899.

21. Day R, McNoe L, Macknight RC: Evaluation of global RNA amplification and its use for high-throughput transcript analysis of laser-microdissected endosperm. International Journal ofPlant Genomics 2007, 1-17.

22. Wilson $\mathrm{CL}$, Pepper SD, Hey Y, Miller CJ: Amplification protocols introduce systematic but reproducible errors into gene expression studies. Biotechniques 2004, 36:498-506. 
23. Dumur Cl, Garrett CT, Archer KJ, Nasim S, Wilkinson DS, Ferreira-Gonzalez A: Evaluation of a linear amplication method for small samples used on high-density oligonucleotide microarray analysis. Analytical Biochemistry 2004, 331:314-321.

24. Stepanova AN, Yun J, Likhacheva AV, Alonso JM: Multilevel interactions between ethylene and auxin in Arabidopsis roots. Plant Cell 2007, 19:2169-2185

25. Vanneste S, De Rybel B, Beemster GTS, Ljung K, De Smet I, Van Isterdael G, Naudts M, lida R, Gruissem W, Tasaka M, Inze D, Fukaki H, Beeckman T: Cell cycle progression in the pericycle is not sufficient for SOLITARY ROOT/ IAA14-mediated lateral root initiation in Arabidopsis thaliana. Plant Cell 2005, 17:3035-3050.

26. Liu HF, Zeeberg BR, Qu G, Koru AG, Ferrucci A, Kahn A, Ryan MC, Nuhanovic A, Munson PJ, Reinhold WC, Kane DW, Weinstein JN: AffyProbeMiner: a web resource for computing or retrieving accurately redefined Affymetrix probe sets. Bioinformatics 2007, 23:2385-2390.

27. Huppert $\lrcorner \mathrm{L}$, Balasubramanian $\mathrm{S}$ : Prevalence of quadruplexes in the human genome. Nucleic Acids Research 2005, 33:2908-2916.

28. Carrera E, Holman T, Medhurst A, Dietrich D, Footitt S, Theodoulou FL, Holdsworth MJ: Seed after-ripening is a discrete developmental pathway associated with specific gene networks in Arabidopsis. Plant Journal 2008, 53:214-224.

29. Deng XW, Caspar T, Quail PH: Cop1 - A Regulatory Locus Involved in Light-Controlled Development and Gene-Expression in Arabidopsis. Genes \& Development 1991, 5:1172-1182.

30. Kawasaki S, Borchert C, Deyholos M, Wang H, Brazille S, Kawai K, Galbraith D, Bohnert HJ: Gene expression profiles during the initial phase of salt stress in rice. Plant Cell 2001, 13:889-905.

31. Schenk PM, Kazan K, Wilson I, Anderson JP, Richmond T, Somerville SC, Manners JM: Coordinated plant defense responses in Arabidopsis revealed by microarray analysis. Proceedings of the National Academy of Sciences of the United States of America 2000, 97:11655-11660.

32. Schmid M, Davison TS, Henz SR, Pape UJ, Demar M, Vingron M, Scholkopf B, Weigel D, Lohmann JU: A gene expression map of Arabidopsis thaliana development. Nature Genetics 2005, 37:501-506.

33. Seki M, Narusaka M, Ishida J, Nanjo T, Fujita M, Oono Y, Kamiya A, Nakajima M, Enju A, Sakurai T, Satou M, Akiyama K, Taji T, YamaguchiShinozaki K, Carninci P, Kawai J, Hayashizaki Y, Shinozaki K: Monitoring the expression profiles of 7000 Arabidopsis genes under drought, cold and high-salinity stresses using a full-length cDNA microarray. Plant Journal 2002, 31:279-292.

34. Viale A, Li J, Tiesman J, Hester S, Massimi A, Griffin C, Grills G, Khitrov G, Lilley K, Knudtson K, Ward B, Kornacker K, Chu CY, Auer H, Brooks Al: Big results from small samples: evaluation of amplification protocols for gene expression profiling. J Biomol Tech 2007, 18:150-161.

35. Cahan P, Rovegno F, Mooney D, Newman JC, St Laurent G, McCaffrey TA: Meta-analysis of microarray results: challenges, opportunities, and recommendations for standardization. Gene 2007, 401:12-18.

36. Bammler T, Beyer RP, Bhattacharya S, Boorman GA, Boyles A, Bradford BU, Bumgarner RE, Bushel PR, Chaturvedi K, Choi D, Cunningham ML, Dengs $S$, Dressman HK, Fannin RD, Farun FM, Freedman JH, Fry RC, Harper A, Humble MC, Hurban P, Kavanagh TJ, Kaufmann WK, Kerr KF, Jing L, Lapidus JA, Lasarev MR, Li J, Li YJ, Lobenhofer EK, Lu X, Malek RL, Milton S, Nagalla SR, O'Malley JP, Palmer VS, Pattee P, Paules RS, Perou CM, Phillips K, Qin LX, Qiu Y, Quigley SD, Rodland M, Rusyn I, Samson LD, Schwartz DA, Shi Y, Shin JL, Sieber SO, Slifer S, Speer MC, Spencer PS, Sproles DI, Swenberg JA, Suk WA, Sullivan RC, Tian R, Tennant RW, Todd SA, Tucker CJ, Van Houten B, Weis BK, Xuan S, Zarbl H: Standardizing global gene expression analysis between laboratories and across platforms. Nature Methods 2005, 2:351-356

37. Kadota K, Nakai $Y$, Shimizu K: Ranking differentially expressed genes from Affymetrix gene expression data: methods with reproducibility, sensitivity, and specificity. Algorithms for Molecular Biology 2009, 4:7-13.

38. Shedden K, Chen W, Kuick R, Ghosh D, Macdonald J, Cho KR, Giordano TJ, Gruber SB, Fearon ER, Taylor JMG, Hanash S: Comparison of seven methods for producing Affymetrix expression scores based on false discovery rates in disease profiling data. Bmc Bioinformatics 2005, 6:26-37.

39. Murashige T, Skoog F: A Revised Medium for Rapid Growth and Bio Assays with Tobacco Tissue Cultures. Physiologia Plantarum 1962, 15:473-497.
40. R Development Core Team: R: A Language and Environment for Statistical Computing. Ref Type: Computer Program 2008.

41. Benjamini $Y$, Hochberg $Y$ : Controlling the False Discovery Rate - A Practical and Powerful Approach to Multiple Testing. Journal of the Royal Statistical Society Series B-Methodological 1995, 57:289-300.

doi:10.1186/1746-4811-6-9

Cite this article as: Holman et al: Statistical evaluation of transcriptomic data generated using the Affymetrix one-cycle, two-cycle and IVTExpress RNA labelling protocols with the Arabidopsis ATH1 microarray. Plant Methods 2010 6:9.

\section{Submit your next manuscript to BioMed Central and take full advantage of:}

- Convenient online submission

- Thorough peer review

- No space constraints or color figure charges

- Immediate publication on acceptance

- Inclusion in PubMed, CAS, Scopus and Google Scholar

- Research which is freely available for redistribution

Submit your manuscript at www.biomedcentral.com/submit
Biomed Central 